\section{Income inequality and the prevalence of common mental disorders in Britain}

\author{
SCOTT WEICH, GLYN LEWIS and STEPHEN P. JENKINS
}

\begin{abstract}
Background It has been hypothesised that the association between greater income inequality and increased mortality is mediated by poor psychosocial health.
\end{abstract}

\begin{abstract}
Aims To test the hypothesis that individuals in regions of Britain with the highest income inequality have a higher prevalence of the common mental disorders, after adjusting for individual income.
\end{abstract}

\section{Method Cross-sectional survey of 8191 adults aged 16-75 in private households in England, Wales and Scotland. The prevalence of common mental disorders was assessed using the General Health Questionnaire.}

\section{Results The association between income inequality and prevalence of the common mental disorders varied with individual income level. Among persons with the highest incomes, common mental disorders were more frequent in regions with greater income inequality (as indicated by high Gini coefficient) (adjusted OR I.31, 95\% Cl I.05-1.65; $P=0.02$ ). The opposite was true for those with the lowest incomes.}

\section{Conclusions Income inequality was associated with worse mental health among the most affluent individuals.}

Declaration of interest None.
Individuals with the poorest standard of living experience the highest rates of physical and psychiatric morbidity (Blazer et al, 1994; Meltzer et al, 1995), independent of occupational social class (Davey Smith et al, 1990; Weich \& Lewis, 1998a,b). What is not yet known is whether health is affected by where people live. Income inequality, a population characteristic, is associated with higher mortality (Kaplan et al, 1996; Kennedy et al, 1996; Fiscella \& Franks, 1997; Wilkinson, 1999) and worse self-rated health (Kennedy et al, 1998). Although Wilkinson (1992) suggested that the effects of income inequality may be mediated by adverse psychosocial health, there have been no studies of income inequality and psychiatric morbidity. Our aims were to describe the relationships between income level, income inequality and the prevalence of the common mental disorders in Britain; and to test the hypothesis that individuals in regions of Britain with the highest income inequality have a higher prevalence of the common mental disorders, after adjusting for individual income.

\section{METHODS}

\section{Participants}

Data were gathered as part of the first wave of the British Household Panel Survey (BHPS), in autumn 1991 (Taylor, 1995; Weich \& Lewis, 1998b). The BHPS is an annual survey of a representative sample of individuals in private households in England, Wales and Scotland. Households were selected for the BHPS using a two-stage, implicitly stratified clustered probability design, with postcode sectors as primary sampling units (Taylor, 1995). The population of postcode sectors was first ordered into 18 regions (16 standard regions in England, distinguishing former Metropolitan Counties and Inner and Outer London, plus Wales and Scotland - see Table 1), resulting in a sample broadly representative of regional populations. Interviews were conducted with all members of selected households aged 16 and over. Individual BHPS participants aged 16-75 who completed the General Health Questionnaire (GHQ; Goldberg \& Williams, 1988) were included in this analysis.

\section{Assessment of common mental disorders}

Common mental disorders were assessed using the self-administered 12-item GHQ (Goldberg \& Williams, 1988). The GHQ is a measure of recent changes in one's usual mental state, and although some individuals with chronic symptoms of anxiety and depression may be misclassified, the false negative rate in a previous community study was low (7\%) (Goldberg \& Williams, 1988). We followed previous studies in treating the common mental disorders as a single dimension (Goldberg \& Huxley, 1992; Lewis \& Booth, 1992; Stansfeld \& Marmot, 1992). Each item on the GHQ was scored as present or absent, and those scoring 3 or more (out of 12) were classified as cases (Banks, 1983; Goldberg \& Williams, 1988; Weich $\&$ Lewis, 1998a,b). Although results are presented here for 'cases' of common mental disorders, there was no reason to expect that using GHQ scores as a continuous variable would lead to different results (Anderson $e t$ al, 1993; Weich \& Lewis, 1998a).

\section{Measures of income}

Gross income data, expressed as pounds sterling per week, were collected by source for each BHPS participant, and aggregated for households. Gross income data include earnings from employment, self-employment, savings, investments and private and occupational pensions, and from cash social security and social assistance benefits. Net household income is equal to gross household income less income tax payments, National Insurance contributions and local taxes. These data were constructed for all persons in the survey by means of a simulation model of the tax system (Jarvis \& Jenkins, 1995). BHPS net income data were validated against contemporaneous data from the Family Expenditure Survey (FES), used by the Department of Social Security to compile official income distribution figures for the UK (Jarvis \& Jenkins, 1995).

Wherever possible, BHPS interviewers sought documentary confirmation of income data. Missing gross income data were 
Table I Number of participants, prevalence of common mental disorders (\% cmd), median net current equivalised weekly income (to the nearest $£$ ) and regional Gini coeffcients, in descending order

\begin{tabular}{lccccc}
\hline Region & $n(\%)$ & $\%$ cmd & Median net income $(\ell)$ & Gini & Gini category' \\
\hline Inner London & $360(4.0)$ & 26.1 & 252 & 0.354 & 4 \\
Outer London & $565(6.2)$ & 26.4 & 249 & 0.345 & 4 \\
Merseyside & $206(2.3)$ & 27.2 & 216 & 0.326 & 3 \\
Greater Manchester & $373(4.1)$ & 25.5 & 233 & 0.318 & 3 \\
Rest of North West & $386(4.3)$ & 25.9 & 228 & 0.315 & 3 \\
West Midlands conurbation & $379(4.2)$ & 26.4 & 179 & 0.312 & 3 \\
Scotland & $870(9.6)$ & 24.6 & 221 & 0.310 & 3 \\
Rest of South East & $1625(17.9)$ & 24.1 & 258 & 0.309 & 3 \\
East Anglia & $348(3.8)$ & 17.0 & 210 & 0.307 & 3 \\
East Midlands & $714(7.9)$ & 23.1 & 208 & 0.303 & 2 \\
West Yorkshire & $331(3.7)$ & 25.1 & 201 & 0.296 & 2 \\
Tyne \& Wear & $230(2.5)$ & 23.0 & 209 & 0.293 & 2 \\
Wales & $480(5.3)$ & 31.0 & 210 & 0.293 & 2 \\
Rest of Yorks \& Humberside & $283(3.1)$ & 18.4 & 215 & 0.285 & 2 \\
Rest of West Midlands & $467(5.2)$ & 25.1 & 226 & 0.281 & 1 \\
Rest of North & $366(4.0)$ & 26.0 & 220 & 0.279 & 1 \\
South West & $814(9.0)$ & 22.7 & 215 & 0.271 & 1 \\
South Yorkshire & $267(3.0)$ & 27.0 & 223 & 0.270 & 1 \\
All & $9064(100)$ & 24.6 & 237 & 0.313 & \\
\hline I. Cat & 2615 & & & \\
\hline
\end{tabular}

I. Category of Gini coefficient, I (lowest) to 4 (highest) used in Table 2 (see Methods).

imputed by the BHPS investigators (Taylor, 1995; Weich \& Lewis, 1998a). These values were used to reduce potential bias arising from the exclusion of missing data. Net income data could not be estimated for the small number of households in which one or more adults refused to be interviewed, because imputed values for missing income components are not available.

All income data were adjusted using the McClements (before housing costs) Equivalence Scale (Taylor, 1995), to take account of differences in household size and composition. In keeping with standard practice (Jarvis \& Jenkins, 1995), each individual was attributed with the equivalent (net or gross) income of the household to which he or she belonged.

Participants were classified in two ways according to their income. First, individuals were allocated to one of 11 bands, starting at $<£ 100$ per week and increasing in increments of $£ 50$ per week. Second, individuals were classified by income rank, by quintile group within region (Weich \& Lewis, $1998 a, b)$. At the time of writing, the exchange rate was approximately $£ 1=0.7$ euro.

\section{Measure of income inequality, by region}

Gini coefficients for each region were calculated using a program written by one of the authors (S.P.J.) (Jenkins, 1999). The Gini coefficient is a measure of inequality that ranges from 0.0 when everyone has the same income (perfect equality) to 1.0 when one person has all the income (perfect inequality). We used the Gini coefficient because it is the most widely used summary measure of income inequality and has a neat relationship with the Lorenz curve for incomes. This measure also has the advantage of being relatively insensitive to the presence of outlier incomes at the top and bottom of the income distribution. Although there are many measures of income inequality, all are highly correlated with one another, and similar in their correlations with mortality (Kawachi \& Kennedy, 1997). We evaluated the sensitivity of our findings to the choice of inequality measure by repeating our analyses using three other inequality indices (the mean log deviation, the Theil index and half the squared coefficient of variation). These indices are members of the generalised entropy class of inequality indices with parameters 0,1 and 2 respectively (Jenkins, 1999). These income inequality indices aggregate income differences among high, middle and poor incomes in different ways. Given that income was not normally distributed, median net income was chosen as the indicator of the central tendency of income distribution within each region.
Regional Gini coefficients were calculated for current gross and net income, using the entire BHPS wave 1 sample, and divided into four categories. Category 1 ('low Gini coefficient') included regions with Gini coefficients less than one standard deviation below the mean; category 2 included regions with coefficients within one standard deviation below the mean; category 3 included regions with coefficients within one standard deviation above the mean; and category 4 ('high Gini coefficient') included regions with coefficients in excess of one standard deviation above the mean (Table 1 ).

\section{Other potential confounders}

Based on previous findings (Weich \& Lewis, 1998a,b), age, gender, housing tenure, Registrar General's social class by head of household, marital status, education, employment, ethnicity, and the number of current physical health problems for each participant were included as potential individual-level confounders of any association between income inequality and common mental disorders.

\section{Statistical analysis}

All analyses were undertaken using Stata (Stata Corporation, 1999). Unadjusted and adjusted odds ratios with $95 \%$ confidence intervals, and likelihood ratio tests (LRTs) to assess departure from linear trends, confounding and effect modification were calculated by means of logistic regression. Since data were clustered within both households and regions, we adjusted the standard errors of regression coefficients using the Huber-White sandwich estimate of variance (Huber, 1981; Stata Corporation, 1999), specifying region as the highest-level cluster. This method relaxes the assumption of independence of observations within clusters. Since it is insensitive to the correlation structures within the highest-level cluster, it also corrects standard errors for any clustering of data at all nested levels below that specified.

Analyses were undertaken separately using both net and gross (individual) income level, and Gini coefficients calculated using distributions of both net and gross income. Except where findings differed, results are presented only for analyses using individual and regional indices based on net income, since these were judged a priori to be the most valid indices of individual and regional income, after 
allowing for the redistributive effects of taxation.

\section{RESULTS}

After excluding 'deadwood' addresses, $73.6 \%$ of households $(n=5511)$ participated in the first BHPS wave, comprising 9612 individuals aged 16-75. Estimates of current gross income were available for the entire sample. Estimates of current net income were available for 4826 households (87.6\%), and 8371 individuals aged 16-75. In total, 8191 participants were included in the present analyses, amounting to $85.2 \%$ of those aged 16-75 who were interviewed at wave 1 of the BHPS, or approximately $63 \%$ of the non-deadwood issued sample for this survey (assuming similarity in the age distributions of participants and nonparticipants). The prevalence of common mental disorders in the study sample was $24.6 \%$ (95\% CI 23.7-25.5).

\section{Income inequality by region}

The median Gini coefficient by region (using net income) was 0.309 (range 0.270-0.354) (Table 1). Two regions (Inner and Outer London) were classified as 'high Gini' regions, and four as 'low Gini' regions (South Yorkshire, Southwest, Rest of North and Rest of West Midlands). Statistically significant associations were found between (higher) Gini coefficients and the proportion of participants living in rented accommodation $\left(\chi^{2}=57.2\right.$, d.f. $=3, P<0.001$ ) and unemployed (for net income, $\chi^{2}=13.0$, d.f. $=3, P=0.005$ ). Regions with higher Gini coefficients had a higher proportion of residents with at least one educational qualification (for net income, $\chi^{2}=36.5$, d.f. $=3, P<0.001$ ), and higher median (net) regional income (Spearman's $r=0.46, P<0.0001$ ).

\section{Individual income, median regional income and prevalence of the common mental disorders}

A statistically significant association was found between the prevalence of the common mental disorders and current net income, which departed from linearity to a statistically significant degree - LRT $\chi^{2}=39.0$, d.f. $=9, P<0.0001$ (Fig. 1). A similar association was found using current gross income. There was no evidence of a statistically significant association between the prevalence of the common mental disorders and median regional net income, whether treated as a continuous or as a categorical measure.

\section{Income inequality and prevalence of the common mental disorders}

No statistically significant association was found between Gini coefficient and the common mental disorders (for Gini category $4 v$. category 1 , unadjusted $\mathrm{OR}=0.99,95 \%$ CI $0.87-1.13 ; P=0.88$ ) However, a statistically significant interaction was found between income level (whether absolute or rank) and regional Gini coefficients in their associations with the prevalence of the common mental disorders (LRT $\chi^{2}$ on removing interaction term $=4.39$, d.f. $=1 ; P=0.04$ ) (Table 2). Odds ratios for the association between Gini coefficient category and the prevalence of the common mental disorders increased with individual income, irrespective of how the latter was measured. Among those with the highest incomes, the prevalence of the common mental disorders was significantly higher among individuals living in 'high Gini' than in 'low Gini' regions, after adjusting for potential individual-level confounders. Among those with the lowest incomes the reverse was true, such that the prevalence of these disorders was lower in 'high Gini' than 'low Gini' regions, to a statistically significant degree. These findings were not altered substantially on adjusting for other potential confounders (Table 2). Finally, sensitivity analyses indicated that our findings were not altered by the choice of inequality measure (see Methods).

\section{DISCUSSION}

\section{Main findings}

The two most notable findings were the non-linear association between income and the common mental disorders, and the statistically significant interaction between income inequality and income level in their associations with the prevalence of these disorders. The use of net rather than gross income to calculate income inequality and to quantify individual financial resources did not alter these findings.

The interaction between income level and income inequality makes it difficult to summarise the relative importance of each for the prevalence of the common mental disorders. In all but those regions with the highest income inequality (the two London regions), low income level was associated with an increase in the risk of being a case of the common mental disorders by between $60 \%$ and $110 \%$. Among those with the highest income levels, the increased risk of the common mental disorders among those living in regions with the highest income inequality, compared with their counterparts in the most egalitarian regions, was about $35 \%$.

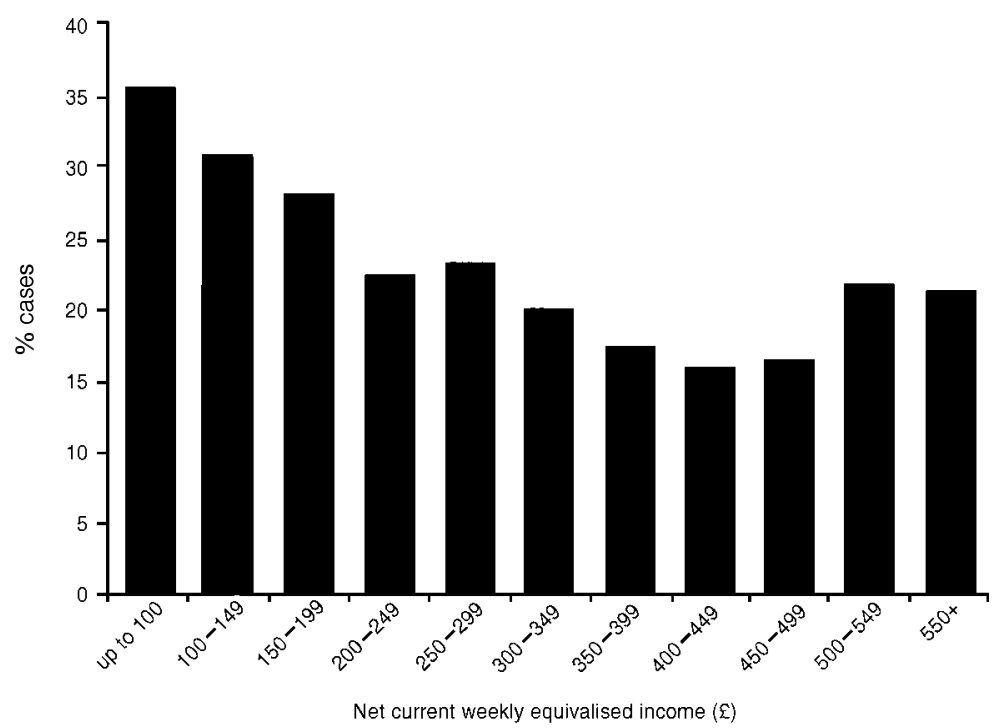

Fig. I Prevalence of the common mental disorders by net current weekly equivalised income. 
Table 2 Percentage of participants who were cases of the common mental disorders, and adjusted odds ratio ( $95 \% \mathrm{Cl}$ ') for prevalence of the common mental disorders by category of Gini coefficient calculated using net current income, stratified by household (net) income rank (fifths within region). The odds of being a case for each group were compared with those for participants in the top income fifth in regions with the lowest Gini coefficients (>I standard deviation below the mean for the entire British Household Panel Survey sample at wave I)

\begin{tabular}{|c|c|c|c|c|c|c|c|c|c|}
\hline \multirow[t]{3}{*}{ Gini category } & \multicolumn{9}{|c|}{ Net income rank by fifths within region } \\
\hline & \multicolumn{3}{|c|}{ Top fifth } & \multicolumn{3}{|c|}{ Middle three-fifths } & \multicolumn{3}{|c|}{ Bottom fifth } \\
\hline & $\begin{array}{c}n \\
(\% \text { cases })^{2}\end{array}$ & $\begin{array}{c}\text { Adjusted OR } \\
(95 \% \mathrm{Cl})\end{array}$ & $P$ & $\begin{array}{c}n \\
(\% \text { cases })^{2}\end{array}$ & $\begin{array}{l}\text { Adjusted OR } \\
\qquad(95 \% \mathrm{Cl})\end{array}$ & $P$ & $\begin{array}{c}n \\
(\% \text { cases })^{2}\end{array}$ & $\begin{array}{l}\text { Adjusted OR } \\
\qquad(95 \% \mathrm{Cl})\end{array}$ & $P$ \\
\hline I (Low) & $367(16.1)$ & 1.00 & & $1058(23.5)$ & $1.36(1.05-1.76)$ & 0.02 & $332(37.7)$ & $2.06(1.67-2.53)$ & $<0.001$ \\
\hline 2 & $386(18.1)$ & $1.10(0.76-1.61)$ & 0.61 & II 35 (24.2) & $1.37(1.01-1.86)$ & 0.04 & 344 (29.9) & $1.59(1.08-2.36)$ & 0.02 \\
\hline 3 & $792(19.1)$ & $1.26(0.97-1.62)$ & 0.08 & $2315(23.4)$ & I.4I (I.I4-I.75) & 0.002 & $673(33.9)$ & $1.99(1.55-2.54)$ & $<0.001$ \\
\hline 4 (High) & $161(20.1)$ & $1.31(1.05-1.65)$ & 0.02 & $495(25.1)$ & $1.29(1.04-1.60)$ & 0.02 & $133(27.1)$ & $0.87(0.64-1.18)$ & 0.37 \\
\hline High v. Low (unadjusted) ${ }^{3}$ & $1706(18.4)$ & $1.35(1.06-1.70)$ & 0.01 & $5003(23.8)$ & $1.09(0.94-1.26)$ & 0.28 & $1482(33.2)$ & $0.61(0.48-0.79)$ & $<0.001$ \\
\hline High v. Low (adjusted) $)^{1,3}$ & & $1.31(1.05-1.65)$ & 0.02 & & $0.95(0.80-1.13)$ & 0.58 & & $0.42(0.31-0.57)$ & $<0.001$ \\
\hline
\end{tabular}

I. Odds ratios adjusted for age, gender, social class, housing tenure, social class by head of household, the interaction between age and social class (Weich \& Lewis, 1998b), employment status, education, ethnicity and number of physical health problems.

2. Total number of participants in each cell of the table and (unadjusted) percentage of participants in each cell (Gini category) by income quintile group who met case criteria for the common mental disorders.

3. Odds ratio for the prevalence of the common mental disorders for those in Gini category compared with participants in Gini category I, for each of the three categories of income rank.

\section{Methodological strengths and weaknesses}

This is the first study to consider the effects of income inequality on rates of psychiatric morbidity, and moreover we are not aware of any other studies that have considered the effects of income inequality on health within Britain. This is also one of the first studies to estimate income inequality after the redistributive effects of taxation, using net income data. Finally, the present study was one of only a handful to control for household income, using the individual as the unit of analysis (Fiscella \& Franks, 1997; Kennedy et al, 1998).

These findings are based on a crosssectional survey, which precludes causal inference. Bias in the recall of income was unlikely, given reliance on documentation wherever possible. Selective migration of wealthy cases of the common mental disorders to regions with the greatest income inequality seems improbable. Although the common mental disorders may contribute to income inequality through economic inactivity or unemployment, the effect of this was likely to have been small. Furthermore, the data used to calculate Gini coefficients were drawn from the entire BHPS wave 1 sample, and not just participants included in our analyses. Regional differences in the extent and distribution of undeclared income may have resulted in biased estimates of income inequality, although little is known about this subject. We are not aware of any evidence that undeclared income varies by region or income level, and there is no reason to suspect that the BHPS is any worse (or better) than other national household surveys at measuring income (Jarvis \& Jenkins, 1995). Nonresponse bias cannot be dismissed, since our sample was about $65 \%$ of the target sample. However, for this to have affected the association between the common mental disorders and income inequality, participation in the first wave of the BHPS would have to have been associated with GHQ score, region of residence and household income.

The GHQ, rather than a standardised clinical interview, was used to assess the common mental disorders. Despite the high sensitivity of the GHQ (Goldberg \& Williams, 1988), the gradient in common mental disorders by individual income may have been underestimated as a result of misclassification of individuals with chronic symptoms of anxiety and depression, and any tendency for those of low socio-economic status to underreport psychiatric symptoms. These were unlikely to have altered our main findings (Goldberg \& Williams, 1988; Newman et al, 1988).

Among the most salient features of any study of this nature are the size of the area over which income data are aggregated
(Kennedy et al, 1998) and the geographical and socio-economic variation across these clusters. Previous studies that have reported statistically significant associations between income inequality and different health outcomes have used data aggregated at the level of countries or US states. While lack of variation in income inequality between UK regions might be a problem, it may be that these regions were too small to permit income inequality to exert an independent effect on health, after adjusting for individual income. Wilkinson (2000) suggests that people in deprived neighbourhoods do not have bad health because of inequalities within neighbourhoods, but because these neighbourhoods are deprived in relation to the wider society. He argues that, in moving from larger to smaller areas, median income becomes a more important predictor, and income inequality a weaker predictor, of mortality. The absence of an association between regional median income and the prevalence of the common mental disorders may perhaps be viewed as further evidence against an area-level effect on individual mental health (Wilkinson, 2000). Our analyses were also conducted at the level of region for pragmatic reasons, in keeping with the structure and organisation of the BHPS data-set. The BHPS data-set contains insufficient observations per district to derive sufficiently reliable estimates of income inequality at 
levels below regions. While acknowledging the limitations that this imposed on our study, and the somewhat artificial nature of the administrative boundaries between regions, we would argue that this is both a theoretically and empirically valid level at which to study the effects of income inequality in Britain.

The range of Gini coefficients in this study was quite a large spread for this index. It was at least as large as the change in the overall Gini coefficient for the United Kingdom from the mid-1970s to the 1990s - a change which is considered by most to have been very large (Lynch et al, 2000). The range of regional Gini scores in the present study was also similar to that observed across US states in the study by Kennedy et al (1998).

\section{Effects of London regions}

Of most concern is the possibility of confounding by other contextual characteristics of the regions, particularly since the two regions with the highest income inequality were Inner and Outer London. The increased prevalence of the common mental disorders among those with the highest incomes in these regions, and the reduced prevalence among those with the lowest incomes, may be due to characteristics of the regions other than income inequality. For example, the stresses experienced by those with the highest incomes may be greater in London than elsewhere because of transport difficulties or higher crime rates. Similarly, the difficulties of life on a low income may be eased in London by greater access to social housing, public transport and other amenities.

\section{Income inequality, higher individual income and worse mental health}

Because the association between individual income level and mortality is non-linear (Wilkinson, 1992), it has been argued that the association between mortality and income inequality in ecological studies may have arisen because areas of high inequality have more poor people (Gravelle, 1998). Two previous studies controlled for household income but produced contradictory results (Fiscella \& Franks, 1997; Kennedy et al, 1998). The latter found that the association between income inequality (using the Gini index) and worse self-rated health increased with lower individual income,

\section{CLINICAL IMPLICATIONS}

- The present study is among the first to provide empirical support for the view that the places where people live affect their mental health, independently of their individual characteristics.

People with higher incomes who lived in regions of Britain with relatively unequal income distributions had a higher prevalence of the common mental disorders than those living in regions where income was more equally distributed. This was not the case for the least well off.

- The association between individual income and prevalence of the common mental disorders was non-linear, and followed a reverse J-shape. Interventions to alleviate the effects of poverty on the prevalence of the common mental disorders are therefore likely to be of greatest benefit if targeted at those on the lowest incomes.

\section{LIMITATIONS}

The cross-sectional study design limits causal inference.

- The use of a self-administered measure of psychiatric morbidity means that a proportion of those identified as 'cases' would not have met diagnostic criteria for clinical disorders.

- The study findings may have been confounded by characteristics of the London regions other than their high income inequality.

SCOTT WEICH, MRCPsych, Department of Psychiatry and Behavioural Sciences, Royal Free and University College Medical School, London; GLYN LEWIS, PhD, Division of Psychological Medicine, University of Wales College of Medicine, Cardiff; STEPHEN P. JENKINS, DPhil, Institute for Social and Economic Research, University of Essex, Colchester

Correspondence: Scott Weich, Senior Lecturer in Psychiatry, Department of Psychiatry and Behavioural Sciences, Royal Free and University College Medical School, Royal Free Campus, Rowland Hill Street, London NW3 2PF. Tel: 0207830 2350; fax: 0207830 2808; e-mail: s.weich@rfc.ucl.ac.uk

(First received 20 March 2000, final revision 24 July 2000, accepted 14 August 2000)

and was attenuated by other individual socio-economic characteristics.

By contrast, we found a modest independent association between regional income inequality and the common mental disorders among those with the highest incomes within their region of residence. This finding was not confounded by individual income or other socio-economic circumstances. Our findings suggest that the most affluent individuals living in areas of highest income inequality experience worse psychosocial health, and hence lower quality of life, than their counterparts in regions where income is distributed more equally. Although not a test of Wilkinson's hypothesis (Wilkinson, 1992) our findings indicate that income inequality may have important public health consequences beyond raised mortality rates. Our findings also run counter to the notion that the most affluent benefit in a highly stratified, competitive and unequal society.

\section{Possible explanations for study findings}

There are many possible explanations for these counter-intuitive results. Although confounding by other contextual factors cannot be excluded, it is possible that those with the highest incomes in regions with higher income inequality may experience greater stresses than the most affluent 
elsewhere. Since a higher income is needed to get into this top income band in regions with the highest income inequality, individuals may have to work harder to maintain their social position. As well as recognising that they have 'further to fall' than counterparts elsewhere, guilt or unease about the relative disadvantage of others may also play a part. These intriguing hypotheses, although speculative, warrant further investigation.

\section{ACKNOWLEDGEMENTS}

The authors are grateful to Richard Wilkinson and Ichiro Kawachi for their comments on earlier drafts of this paper. The data used in this manuscript were made available through the ESRC Data Archive. The data were originally collected by the ESRC Research Centre on Micro-social Change at the University of Essex. Neither the original collectors of the data nor the Archive bear any responsibility for the analyses or interpretations presented here. The Institute for Social and Economic Research receives core funding from the ESRC and the University of Essex.

\section{REFERENCES}

Anderson, J., Huppert, F. \& Rose, G. (1993) Normality, deviance and minor psychiatric morbidity in the community: a population-based approach to General Health Questionnaire data in the Health and Lifestyle Survey. Psychological Medicine, 23, 475-485.

Banks, M. H. (1983) Validation of the General Health Questionnaire in a young community sample. Psychological Medicine, I3, 349-353.

Blazer, D. G., Kessler, R. C., McGonagle, K. A., et al (1994) The prevalence and distribution of major depression in a national community sample: the National Comorbidity Survey. American Journal of Psychiatry, I5I, 979-986.
Davey Smith, G., Bartley, M. \& Blane, D. (1990) The Black Report on socioeconomic inequalities in health 10 years on. British Medical Journal, 30I, 373-377.

Fiscella, K. \& Franks, P. (1997) Poverty or income inequality as predictor of mortality: longitudinal cohort study. British Medical Journal, 314, 1724-1727.

Goldberg, D. \& Huxley, P. (1992) Common Mental Disorders: A Bio-social Model. London: Routledge.

Goldberg, D. P. \& Williams, P. (1988) The User's Guide to the General Health Questionnaire.Windsor: NFER-Nelson.

Gravelle, H. (1998) How much of the relation between population mortality and unequal distribution of income is a statistical artefact? British Medical Journal, 316, 382-385

Huber, P. J. (198I) Robust Statistics. New York: John Wiley \& Sons.

Jarvis, S. \& Jenkins, S. P. (1995) Do the Poor Stay Poor? New Evidence about Income Dynamics from the British Household Panel Survey. Occasional Paper 95-2. Colchester: University of Essex.

Jenkins, S. P. (1999) Analysis of income distributions. Stata Technical Bulletin, 48, 4-18.

Kaplan, G. A., Pamuk, E. R., Lynch, J. W., et al (1996) Inequality in income and mortality in the United States: analysis of mortality and potential pathways. British Medical Journal, 312, 999-1003.

Kawachi, L. \& Kennedy, B. P. (1997) The relationship of income inequality to mortality: does the choice of indicator matter? Social Science and Medicine, 45, |12|-|127.

Kennedy, B. P., Kawachi, I. \& Prothrow-Smith, D. (1996) Income distribution and mortality: crosssectional ecological study of the Robin Hood Index in the United States. British Medical Journal, 312 1004-1007.

_, _, Glass, R., et al (1998) Income distribution socioeconomic status and self-rated health in the United States: multi-level analysis. British Medical Journal, 3 I7, 917-921.
Lewis, G. \& Booth, M. (1992) Regional differences in mental health in Great Britain. Journal of Epidemiology and Community Health, 46, 608-611.

Lynch, J.W., Davey Smith, G., Kaplan, G. A., et al (2000) Income inequality and mortality: importance to health of individual income, psychosocial environment, or maternal conditions. British Medical Journal, 320, 1200-1204.

Meltzer, H., Gill, B. \& Petticrew, M. (1995) OPCS Surveys of Psychiatric Morbidity in Great Britain. Report No I. The Prevalence of Psychiatric Morbidity among Adults Aged 16-64 Living in Private Households in Great Britain. London: HMSO

Newman, S. C., Bland, R. C. \& Orn, H. (1988) A comparison of methods of scoring the General Health Questionnaire. Comprehensive Psychiatry, 29, 402-408.

Stansfeld, S. A. \& Marmot, M. G. (1992) Social class and minor psychiatric disorder in civil servants: a validated screening survey using the General Health Questionnaire. Psychological Medicine, 22, 739-749.

Stata Corporation (1999) Stata Statistical Software: Release 6.0. College Station, Texas: Stata Corporation.

Taylor, M. F. (ed.) (1995) British Household Panel Survey User Manual Volume A: Introduction, Technical Report and Appendices. Colchester: University of Essex.

Weich, S. \& Lewis, G. (1998a) Poverty, unemployment and common mental disorders: population-based cohort study. British Medical Journal, 317, II5-119.

_ \& _ (1998b) Material standard of living, social class and the prevalence of the common mental disorders in Great Britain. Journal of Epidemiology and Community Health, 52, 8-14.

Wilkinson, R. (1992) Income distribution and life expectancy. British Medical Journal, 304, 165-168.

Wilkinson, R. G. (1999) Putting the picture together: prosperity, redistribution, health and welfare. In Socia Determinants of Health (eds M. Marmot \& R. G. Wilkinson), pp. 256-274. Oxford: Oxford University Press.

- (2000) Inequality and the social environment: a reply to Lynch et al. Journal of Epidemiology and Community Health, 54, 4II-4I3. 